\title{
THE IMPORTANCE OF A DEEPER INSIGHT INTO THE BIOCOMPATIBILITY OF MATERIALS AND MEDICAMENTS TO MINIMIZE TOXICITY IN DENTISTRY
}

\author{
Widowati Siswomihardjo \\ Department of Biomaterials Faculty of Dentistry Gadjah Mada University
}

\begin{abstract}
The Importance of a Deeper Insight into the Biocompatibility of Dental Materials and Medicaments to Minimize Toxicity

Nowadays, in the development of materials and medicaments one must not only consider the strength or inctional aspects, but also its biocompatibility. The bio- compatibility of materials and medicaments is one of the main requirements to be considered in treating a patient. The non-toxic effect of a material or medicament is a strict condition as being biocompatible. Almost all dental treatments involve the use of materials and medicaments, of which the basic substances are composed from chemical compounds. The use f chemical substances in the human body can give benefits or cause harm. Toxicity is one of the adverse effects of chemical compounds on living organisms. It is then becoming a problem that there are materials and medicaments which chemically are harmful but still used in dentistry, as there are no other alternatives. In this situation, the best way for dentists to give a save treatment is to get a deeper insight into the of materials and medicaments in dentistry. Indonesian Journal of Dentistry 2006; Edisi Khusus KPPIKG XIV:144-147
\end{abstract}

Key words: biocompatibility, toxic, materials and medicaments

\section{Pendahuluan}

Di bidang kedokteran gigi dalam menangani suatu kasus dapat dipastikan bahwa selain obatobatan juga digunakan bahan atau medikamen, yang dapat digunakan secara langsung sebagai bagian dari tindakan perawatan, atau sebagai penunjang pekerjaan di laboratorium. Dapat dipahami bahwa bahan dan medikamen mempunyai peran yang sama besarnya dengan obat dalam keberhasilan perawatan kedokteran gigi. ${ }^{\text {' }}$

Bahan dan medikamen termasuk biomaterial, yaitu suatu bahan yang non-viable yang dalam pemakaiannya akan berinteraksi dengan sistem biologik atau jaringan hidup. ${ }^{2}$ Perkembangan biomaterial menuntut bahwa pemakaian semua biomaterial tidak hanya mempertimbangkan faktor kekuatan, estetika, atau fungsi saja, tetapi yang juge penting adalah biokmpatibilitasnya. ${ }^{3}$ Dalam art bahwa biomaterial tersebut harus mempunya kemampuan untuk memberikan respons hospes yan: baik dalam kegunannya pada manusia. ${ }^{2}$

Pada dasarnya, semua biomaterial tersusun dar bahan kimia. Pemakaian bahan kimia pada mahlu! hidup dapat memberikan dua macam respon biologik yang berbeda, yaitu memberikan efe menguntungkan atau sebaliknya berakibat meru gikan. Respons biologik yang merugikan antara lai dapat berubah terjadi infeksi, inflamasi, alerg keracunan (toksisitas), bahkan bisa berakib: menjadi tumor ${ }^{2,4}$.

Suatu kenyataan bahwa sampai saat ini mas terdapat bahan atau medikamen yang digunakan kedokteran gigi yang sebenarnya secara kimia 
Modifikasi Ionomer Kaca Konvensional

Sifat mudah terkontaminasi air atau sensitif terhadap keadaan lembab serta kekuatan awal yang rendah mendorong untuk dikembangkannya ionomer kaca dengan reaksi pengerasan yang lebih cepat. Modifikasi dilakukan terhadap komposisi yaitu dengan mengurangi kandungan kalsium sehingga terbentuk material restoratif yang lebih tahan terhadap air. ${ }^{19}$ Modifikasi ini menghasilkan ionomer kaca konvensional viskositas tinggi.

lonomer kaca viskositas tinggi dapat dipakai untuk Atraumatic Restorative Technique (ART). Teknik ini ditujukan untuk dipakai pada negaranegara berkembang yang sarana dan prasarananya terbatas. Karies cukup diekskavasi dengan ekskavator, selanjutnya dibuatkan restorasinya.

\section{Resin Modified Glass Ionomer Cement}

Pada tahun 1988 Antonucci dkk memperkenalkan ionomer kaca sinar yang selanjutnya dikembangkan oleh Mitra (1989). Material ini adalah ionomer kaca konvensional yang dimodifikasi dengan penambahan resin dan diberi nama Resin Modified Glass lonomer Cement (RMGIC). Resin yang dipakai umumnya adalah asam hidroksi etil metakrilat (HEMA), selain itu ada photoinitiator, sejumlah kecil resin lain serta chemical initiator. ${ }^{20.21}$

Reaksi pengerasan RMGIC berlangsung dengan mekanisme ganda yaitu reaksi asam basa dan selanjutnya proses polimerisasi sehingga risiko terkontaminasi air pada awal pengerasan dapat dihilangkan. Apabila RMGIC mengandung chemical initiator maka reaksinya berlangsung secara triple curing mechanism yaitu reaksi asam basa, reaksi kimia, dan polimerisasi penyinaran. ${ }^{21}$

Evaluasi terhadap kekuatan ikat RMGIC dengan struktur gigi telah banyak diteliti. Dinyatakan bahwa penyinaran memberikan efek yang signifikan terhadap nilai bond strength. ${ }^{22.23}$ Hasil penelitian Delbem dkk (2005) terhadap kemampuan RMGIC dalam melepas dan mengambil fluor menunjukkan adanya pelepasan fluor yang sedikit lebih rendah dibandingkan ionomer kaca konvensional. Namun setelah aplikasi topikal APF gel $1,23 \%$ selama 4 menit kemampuan RMGIC melepas fluor meningkat signifikan dibandingkan yang konvensional. Hal ini diduga karena adanya HEMA yang menyerap air sehingga memberi jalan untuk difusi ion-jon fluor. ${ }^{15}$ Demikian juga hasil penelitian Pamir T dkk. (2006) menunjukan bahwa pelepasan fluor kumulatif dari RMGIC lebih besar daripada ionomer kaca konvensional. ${ }^{24}$
Hasil penelitian Lan WH dkk. (2005) terhadap respons pulpa menunjukkan efek toksik RMGIC yang lebih besar dibandingkan yang konvensional. Komponen RMGIC seperti HEMA berkontribusi dalam memberikan efek toksik terhadap pulpa. Demikian juga RMGIC yang mengandung UDMA dan TEGDMA yang efek toksiknya lebih besar dibandingkan HEMA. Dengan demikian sebaiknya RMGIC tidak berkontak dengan pulpa. ${ }^{25}$

\section{Polyacid Modified Composite Resin}

Usaha-usaha memperbaiki sifat-sifat ionomer kaca terus berlanjut. Pada tahun 1993 diperkenalkan material yang diberi nama Polyacid Modified Composite Resin (PMCR) atau lebih dikenal dengan nama Compomer. Komponen pembentuknya adalah komponen yang ada pada ionomer kaca dan matrik Resin Komposit. Compomer tidak dapat bereaksi asam basa sehingga tidak dapat dikatagorikan sebagai ionomer kaca. ${ }^{1,21}$

Compomer tidak dapat berikatan dengan stuktur gigi melalui mekanisme pertukaran ion. Ikatan dengan struktur gigi didapat melalui bonding agent. Dengan demikian, pada dasarnya Compomer adalah resin komposit dengan sedikit potensi melepas fluor yang terjadi setelah beberapa waktu restorasi berada di lingkungan mulut ${ }^{26}$

\section{Giomer}

Pada sekitar tahun 2002 diperkenalkan material baru yang disebut Giomer. Giomer dinyatakan sebagai hibridisasi ionomer kaca dan resin komposit. Material ini dibuat dengan teknologi Pre-Reacted Glass lonomer (PRG) yaitu pre-reaksi fluoroaluminosilicate glass filler dengan polyacrilic acid membentuk fasa stabil wet siliceous hydrogel. Selanjutnya filler ini digabungkan dengan matrik resin. Adanya pre-reacted hydrogel menyebabkan giomer mampu melepas dan mengambil fluor. Giomer dipakai bersama dengan suatu adhesive system berbasis ionomer kaca yang mampu membentuk ikatan hidrogen dengan kolagen dentin. Ada dua jenis Giomer yaitu Full PRG dan Surface PRG. Pada Full PRG seluruh filler bereaksi dengan asam sedangkan Surface PRG hanya pada permukaan saja sehingga masih terdapat suatu glass core. ${ }^{1,27}$

\section{Compomer + Vinyl Phosphonic Acid}

Gabriel dkk (2005) membuat modifikasi Compomer. Tujuannya adalah untuk memperbaiki sifat pemakaian (wear) dan adhesi dengan struktur gigi. Pada Compomer ditambahkan Vinyl Phosphonic Acid (VPA). Ada dua komposisi yang 
dibuat yaitu komposisi A yang monomernya terdiri dari Bis GMA, TEGDMA dan VPA $(13,21: 4,21$ : $0,24)$ dan komposisi $B$ mengandung VPA 10 kali tebih banyak daripada komposisi $\mathrm{A}$.

Hasil uji wear menunjukkan bahwa baik komposisi A maupun B mempunyai sifat wear yang lebih baik dibandingkan resin komposit komersial (Dyract) dan di antara keduanya yang terbaik adalah komposisi A. Demikian juga dengan derajat polimerisasinya. Semakin tinggi jumlah VPA semakin rendah derajat polimerisasinya. Hal ini menunjukkan bahwa radikal bebas yang diakhiri dengan unit VPA refatif stabil. Sehingga dengan demikian VPA dapat dipakai sebagai acid functional monomer di dalam Compomer namun hanya dalam jumlah kecil yaitu kurang dari $0,25 \%$ dari total komposisi. Lebih besar dari $0,25 \%$ akan menghambat proses polimerisasi adisi. 28

\section{Ionomer Kaca + Bioactive Glass}

Yli-Urpo dkk. membuat Glass lonomer yang dimodifikasi dengan penambahan partikel gelas bioaktif (BAG). Hasilnya menunjukkan bahwa ionomer kaca (Gl) + BAG (GI + BAG) mempunyai efek bioaktif pada larutan fisiologis dan mampu memineralisasi dentin secara in vitro. Selain itu pada penelitiannya juga didapat bahwa GI + BAG mempunyai efek antimikroba. ${ }^{29,30}$

Pada penelitian selanjutnya (2005) dilakukan uji kuat tekan pada GI + BAG dan RMGIC + BAG. Sebagai pembanding dipakai GI dan RMGIC tanpa BAG. Sebelum diuji spesimen direndam dalam air seiama 6 bulan. Hasil penelitiannya menunjukkan bahwa penambahan BAG dapat menurunkan kuat tekan baik pada Gl maupun RMGIC dan penurunannya sangat signifikan. Berdasarkan hasil penelitian ini dianjurkan untuk pemakaian klinis GI +BAG dipakai apabila diperlukan adanya bioakitfitas misalnya untuk root surface filling dan liners sementara kuat tekan tidak terialu diperlukan. ${ }^{31}$

\section{Performa Klinis Material Restoratif Ionomer Kaca}

Evaluasi performa klinis suatu material restoratif perlu dilakukan untuk pertimbangan pengembangan material dan menentukan kapan dilakukan re-intervention. Berbagai pertimbangan seperti pain-free treatment, prediksi umur restorasi, dan biaya perawatan berpengaruh terhadap kepuasan pasien terhadap restorasinya.

Public Health Services Amerika (USPHS) membuat kriteria yang dapat dipakai untuk mengevaluasi performa klinis suatu restorasi. Ada pun yang dievaluasi antara lain retensi (lepas/ tidaknya restorasi), perubahan warna tepi restorasi, bentuk anatomi, adaptasi tepi restorasi, tekstur permukaan dan karies sekunder yang terjadi.

Lucarotti dkk (2005) mengevaluasi beberapa material restoratif di antaranya ionomer kaca. Setelah satu tahun, restorasi ionomer kaca yang bertahan adalah $84 \%$, menjadi $53 \%$ setelah 5 tahun, dan $38 \%$ setelah 10 tahun (resin komposit $43 \%$ ). Kedua material tersebut dipakai sebagai restorasi kelas III dan V, jadi tidak ditempatkan pada loadbearing area. Material restoratif ini diharapkan ditempatkan pada minimal intervention conities yang lebih mengutamakan sifat adhesi ionomer kaca atau sebagai restorasi transisi, sementara aktivitas karjes dikontrol. ${ }^{32}$

Evaluasi performa klinis terhadap material restoratif RMGIC (caries-free cervical lesions) selama dua tahun telah dilakukan oleh Brackett WW dkk. (2003). Hasilnya menunjukkan bahwa retensi dan adaptasi tepi restorasi RMGIC mencapai $96 \%$ (resin komposit 81\%). Namun dalam ha! kecocokan warna (color match), resin komposit lebih baik daripada RMGIC. ${ }^{33}$

Gallo dkk (2005) melakukan evaluasi klinis selama 3 tahun terhadap perubahan warna tepi restorasi, bentuk anatomi, adaptasi tepi restorasi, tekstur permukaan,retensi dan karies sekunder restorasi Compomer non caries cervical lesion. Hasit yang didapat menunjukkan adaptasi mernburuk dimulai setelah tahun pertama meskipun retensinya $96,6 \%$. Perubahan warna tepi $82,1 \%$, tekstur permukaan $50 \%$, bentuk anatomi $46,6 \%$ dan karies sekunder $100 \%$. Hasil ini menunjukkan Compomer cukup sukses dipakai selama 3 tahun untuk non caries cervical lesion. ${ }^{34}$

Dua produk Giomer yang beredar dipasaran yaitu FPRG Reactmer (Shofu) untuk cervical lesion dan Beautifil SPRG untuk cervical dan occlusal lesion dievaluasi oleh Sunico dkk (2005) selama 2 tahun. Hasilnya restorasi cervical Beautifil dapat bertahan sedangkan restorasi occlusal mengalami sedikit perubahan pada adaptasi dan warna tepi restorasi serta bentuk anatomisnya namun tetap dalam katagori sukșes berdasarkan kriteria USPHS. Reactmer yang dipakai untuk cervical lesion tidak terlalu sukses dibandingkan Beautifil. Penyerapan air dan kelarutan Reactmer cukup tinggi. Oleh karena itu Giomer jenis FPRG perlu ditinjau dan diperbaiki lagi untuk meningkatkan sifat-sifatnya. ${ }^{27}$ 


\section{Kesiapulan}

Dari urajan tersebut di atas material restoratif :arez Japat dikatagorikan sebagai ionomer kaca tatah material yang mampu bereaksi asam basa. Zerbagai pengembangan dan modifikasi telah - -ikukan namun yang dapat digolongkan sebagai womer kaca adalah ionomer kaca konvensional dan Psin hodified Glass Ionomer. Kedua material zampu berikatan dengan stuktur gigi melalui -zekanisme pertukaran ion sehingga didapat adaptasi $\Rightarrow$ i yang baik dan mengeliminasi kebocoran tepi. Material juga bertindak sebagai reservoir fluor sehingga menjadi sumber untuk remineralisasi struktur gigi yang mengalami demineralisasi, dengan jernikjan sekunder karies dapat dicegah. Selain itu mampu mencegah pembentukan plak dan bersifat bioaktif. Namun kedua material ini sebaiknya tidak anempatkan pada load bearing area dan hanya jupakai untuk caries-free cervical lesion.

\section{Daftar Acuan}

Mount GJ and Hume WR. Preservation and Restoration of Tooth Structure. $2^{\text {nd }}$ ed. China: Knowledge Books and Soltware, 2005: 163-190.

: Mount GJ. Minimal Intervention Dentistry: Rationale of Cavity Design. Op Dent 2003:28:92-9.

$3 \quad$ Ten Cate MM. "In Vitro" Studies on the Effect of Fluoride on De-and Remineralization. J Dent Res I990:69:614-9.

4 Ngo H, Marino V and Mount GJ. Calcium, Strontium, Aluminum, Sodjum and Release and Uptake by Glass Ionomers and Related Materials and Its Chemical Effect. Fluoride Release from Four Glass Ionomer. $J$ Dent Res 1998:77 Abstract (75):641

$5 \quad$ Wilson $\mathrm{AD}$ and Kent BE. A New Transiucent Cement for Dentıstry. Br Dental J 1972:132:133-5.

b Nicholson JW. Chemistry of Glass Ionomer Cements: A Review. Biomaterials 1998:19:485-94.

Davidson $\mathrm{CL}$ and Mjor IA. Advanced in Glass Ionomer Cements. 1" ed Germany: Quintessence Publishing Co. Inc, 1999:15-45.

8 Akinmade $\mathrm{AD}$ and Nicholson JW. Review: Glass Ionomer Cement as Adhesives. Part 1. Fundamental Aspects and Their Clinical Relevance. J Mat Sci Med 1993:4:95-101.

9. Akinmade $\mathrm{AD}$. Adhesion of Glass Polyalkenoat Cement to Collagen. J Dent Res 1994; Abstract (638): 181.

10 Wilson $A D$ and Posser $H J$. Biocompatibility of the Glass lonomer Cement. $J$ Dent South Africa 1982;37:872-9.

11. Forsten L. Fluoride Release of Glass lonomers. $J$ Esthet Dent 1994;6:216-22.

12. E1 Mallakh BF and Sarkar NK. Fluoride Release from Glass lonomer Cement in De-Ionized Water and Artificial Saliva. Dent Mater 1990;6(2):118-22.

13. Forsten L. Fluoride Biomaterials 1998;19:503-8.

14. Forss H. Release of Fluoride and Other Elements from Light Cured Glass Ionomer in Neutral and Acidic Conditions. $J$ Dent Res 1993;72:1257-62
15. Delbem ACB, Pedrini D, Franca JGM and Machado TM Fluoride Release/recharge from Restorative Materials Eflect of Fluoride Gets and Time. Op Dent 2005:30-5:690. 5.

16. Suanbery M. Mjor IA and Orstavik P. Mutans Streptococcus in Plaque from Margins of Amalyam, Composite and Glass Ionomer Restoratives. J Dent Res 1990;69:861-4.

17. Ten Cate JM and Van Duinen RNB. Hypermineralization of Dentinal Lesions Adjacent to Glass Ionomer Cement Restorations. J Dent Res 1995;74: 1266-71.

18. Exterkate RAM, Damen JJM and Ten Cate JM. Effect of Fluoride-Releasing Filling Materials on Underlying Dentinal Lesions in Vitro. Caries Res 2005:39:509-13.

19. Mount GJ. Glass Ionomers: A Review of Their Current Status. Op Dent 1999:24(2): 115-24.

20. Antonucci JM, Mc Kenney JE, and Starsburg JW. US Pat: Appln No. 160856, 1998.

21. Mc Lean JW. Evolution of Glass lonomer Cements: A Personal View. J Esthetic Dent 1994;6:195-206.

22. Fried $\mathrm{KH}$ and Powers JM. Bond Strength of lonomers Affected by Dentin Depth Ant Moisture. I Dent Res 1994:73 Abstract (653):183.

23. Chalton DG and Haveman $\mathrm{CW}$. Dentin Surface Treatment and Bond Strength of Glass Jonomer. Am J Dent 1994:7:479.

24. Pamix T, Tezel H, Ozata $F$ and Celik A. Fluoride Release from Esthetic Restorative Materials with and without Adhesive. Quintessence Int 2006;37:145-150.

25. Lan WH, Lan WC, Wang TM, Lee YL, Tseng WY et al. Cytotoxicity of Conventional and Modified Glass lonomer Cements. Op Dent 2003;28-3:251-9.

26. Davidson $\mathrm{CL}$ and Mjor IA. Advances in Glass Ionomer Cements. $1^{\text {s }}$ ed. Germany: Quintessence Publishing Co Inc, 1999:44-7.

27. Sinico MC, Shinkai $K$ and Katoh Y. Two Year Clinical Performance of Occlusal and Cervical Giomer Restorations. Op Dent 2005;30-3:282-9.

28. Gabriel DA, Aduri GA, Deb $S$ and Nichotson JW. A Preliminary Study of Experimental Polyacid Modified Composite Resin ("Compomer") Containing Vinyl Phosphonic Acid. Dent Mater 2005;21:491-7.

29. Yli-Urpo H, Forsback AP, Vakiparta M, Vallittu PK and Narhi T. Release of Silica, Calcium, Phoshorous and Fluoride from Glass lonomer Containing Bioactive Cilass. Biomater Appl 2004;19:5-20.

30. Yli-Urpo H, Narhi T, Soderling E. Antimicrobial Effects of Glass ionomer Cement Containing Bioactive Giass (S53P4) on Oral Microorganism in Vitro. Acta Odontol Scand $2003 ; 6: 24 t-6$.

31. Yli-Urpo H, Lassila LVJ, Narhi T, Valtittu PK Compressive Strength and Surface Characterization of Glass lonomer Cements Modified by Particles Of Bioactive Glass. Dent Mater 2005:21:201-9.

32. Lucarotti PSK, Holder RL and Burke FJT. Outcome of Direct Restorations Placed within The General Dental Services in England and Wales (Part 1): Variation by type of restoration and re-intervention. $J$ Dent 2005:33:805-15.

33. Brackett WW, Dib A and Brackett MG. Two-year Clinical Performance of Class V Resin-Modified Glass-lonomer and Resin Composite Restorations. Op Dent 2003;28-5:477-81.

34. Galko JR, Burgess JO, Ripps Ah, Walker RS, Ireland Ej et al. Three-year Clinical Evaluation of A Compomer and A Resin Composite As Class V Filling Materials. Op Dent 2005;30-3:275-81. 